\title{
Mortality from dementias and neurodegenerative disorders in people aged 15-64 in England and Wales in 1979-96
}

\author{
Azeem Majeed, Petra Lehmann, Liz Kirby, Michel P Coleman
}

Office for National Statistics, London SW1V 2QQ Azeem Majeed, medical epidemiologist Petra Lehmann, research officer Liz Kirby, research officer Michel P Coleman, deputy chief medical statistician

Correspondence to: Dr Majeed azeem.majeed@ons. gov.uk

BMJ 1998;317:320-1

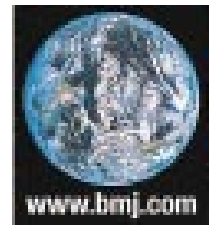

Appendix appears on our website
There is now good evidence that the new variant of Creutzfeldt-Jakob disease first identified in 1996 is caused by exposure to bovine spongiform encephalopathy (BSE). ${ }^{1-3}$ Because Creutzfeldt-Jakob disease can be difficult to diagnose, it is possible that cases of sporadic and new variant Creutzfeldt-Jakob disease have occurred that were not correctly diagnosed because postmortem or neuropathological examinations were not performed. In such cases patients could have been certified as dying from another dementia or a neurodegenerative disease. If this had occurred, mortality from Creutzfeldt-Jakob disease would have been underestimated, with a corresponding increase in mortality from other dementias and neurodegenerative disorders. We investigated whether there had been any increase in mortality from dementias and neurodegenerative disorders since 1979 .

\section{Methods and results}

We obtained the number of deaths from selected dementias and neurodegenerative disorders (see appendix on $B M J$ website) in 5 year age groups in people aged 15-64 years living in England and Wales during 1979-96. We excluded deaths in older people because the large number of deaths from senile dementia and Alzheimer's disease would have made it difficult to detect a relatively small increase in deaths from other dementias and neurodegenerative disorders and because death certification is less accurate in elderly people. ${ }^{4}$

Using the 5 year age bands, we then calculated mortality directly standardised for age for each year, using the population of England and Wales in 1979 as the standard population. Because changes in the coding of death certificates in 1984 and 1993 led to artefactual changes in mortality for neurological disorders, we present results separately for the periods 1979-83, 1984-92, and 1993-6.

We found 7796 deaths from dementias and neurodegenerative disorders for study. The commonest diagnoses were senile and presenile dementias (2074 deaths), cerebral degenerations (1924), and extrapyramidal disorders (1797). During 1979-83 (1628 deaths) directly standardised mortality changed little, being 10.4 and 10.0 per million in 1979 and 1983 respectively (figure). Between 1984 and 1992 (4574 deaths), when the population was first known to have been exposed to BSE infected material, mortality decreased from 17.0 to 14.7 per million. During 1993-6 (1594 deaths), mortality increased from 11.1 per million in 1993 to 13.3 in 1995 before falling to 12.6 in 1996.

For statistical analysis, we split the study period into four groups (1979-83, 1984-7, 1988-92, 1993-6). Analysis of covariance was done with mortality as the dependent variable and group, year, and group $\times$ year interaction as factors. This enabled us to estimate separate slopes for each group. The interaction was significant $(\mathrm{P}=0.03)$, suggesting that the slope of rate against

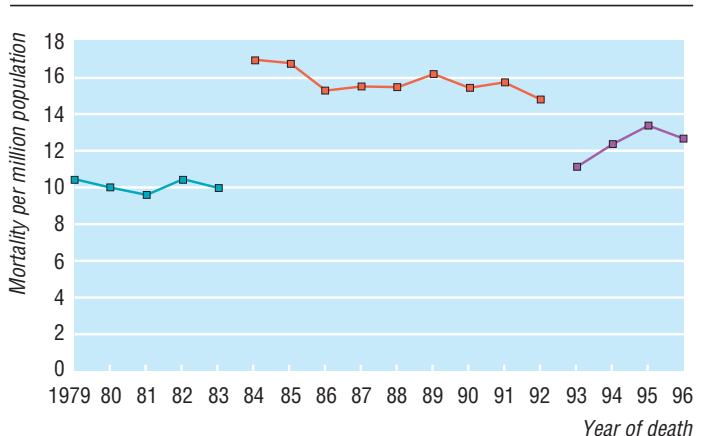

Age standardised mortality from selected dementias and neurodegenerative disorders in people aged 15-64 in England and Wales during 1979-96

time had changed over the study period. The only positive slope was between 1993 and 1996 (slope $=0.53,95 \%$ confidence interval 0.03 to 1.04 ).

\section{Comment}

There was no evidence for any increase in mortality from dementias and neurodegenerative disorders in 15-64 year olds during 1979-92. There was, however, a small but statistically significant increase during 1993-6. Because of the limitations of routine mortality statistics, it is not possible to say with any certainty what the cause of the increase was. Our findings suggest, though, that greater surveillance of deaths from dementias and neurodegenerative disorders may be needed to avoid missing possible BSE associated deaths.

Now that the link between BSE and CreutzfeldtJakob disease is fairly well established it is likely that further cases of new variant Creutzfeldt-Jakob disease will be identified in the future. However, because the length and variability of the incubation period for development of new variant Creutzfeldt-Jakob disease remain unknown, only limited conclusions can be made as to the total number of BSE related deaths that will occur. ${ }^{5}$ The Office for National Statistics will therefore continue to monitor death rates from dementias. Research is also under way to identify any cases of Creutzfeldt-Jakob disease that may have been missed in people aged under 45 dying from a dementing illness during 1979-96.

We thank Dr James Ironside and Dr Richard Knight from the National CJD Surveillance Unit for their help in defining the group of diseases for study, and Professor Martin Bland for help with the statistical analysis.

Contributors: AM and MPC planned the study. PL and LK carried out the analysis. AM wrote the paper, with comments from MPC, PL, and LK. AM and MPC are the guarantors for the paper. Funding: Department of Health and Medical Research Council.

Conflict of interest: None.

1 Will RG, Ironside JW, Zeidler M, Cousens SN, Estibeiro K, Alperovitch A, et al. A new variant of Creutzfeldt-Jakob disease in the UK. Lancet 1996;347:921-5. 
2 Bruce M, Will RG, Ironside JW, McConnell I, Drummond D, Suttie A, et al. Transmissions to mice indicate that 'new variant' CJD is caused by the BSE agent. Nature 1997;389:498-501.

3 Hill AF, Desbruslais M, Joiner S, Sidle KCL, Gowland I, Collinge J, et al The same prion strain causes VCJD and BSE. Nature 1997;389:448-50.
4 Homer AC, Honaver M, Lantos PL, Hastie IR, Kellett JM, Millard PH Diagnosing dementia: do we get it right? BMJ 1988;297:894-6.

5 Cousens SN, Vynnycky E, Zeidler M, Will RG, Smith PG. Predicting the CJD epidemic in humans. Nature 1997;385:197-8.

(Accepted 6 March 1998)

\section{Diagnosing fever by touch: observational study}

\author{
Katherine Whybrew, Matthew Murray, Colin Morley
}

Fever is a useful indicator of whether a child is seriously ill. ${ }^{1}$ Many mothers and doctors estimate children's temperature by touch. ${ }^{2}$ We assessed whether mothers and medical students could use touch to determine if children had fever.

\section{Subjects, methods, and results}

During their elective in a Zambian hospital, medical students and the child's mother felt children's abdomen, forehead, and neck and independently recorded whether the child felt hot. Simultaneously, a mercury thermometer was used to measure axillary temperature for exactly 3 minutes. Rectal temperature measurement was not permitted at this hospital.

In total, 1090 children aged 1 month to 16 years (median 2 years) were studied. The mean ambient temperature was $24.5(\mathrm{SD} 2.0)^{\circ} \mathrm{C}$; the mean axillary temperature from 24 children not recently vaccinated and with no complaint was 36.7 (2SD 1.12$)^{\circ} \mathrm{C}$. Therefore $37.8^{\circ} \mathrm{C}$ or higher was defined as a fever. With this definition, 236 (27\%) children had fever.

The mothers assessed 862 children and thought $574(67 \%)$ were warm or hot. Their sensitivity was $94 \%$ (221/236), specificity 44\% (273/626), positive predictive value $39 \%(221 / 574)$, and negative predictive value $95 \%(273 / 288)$.

Two students assessed 1086 children and thought $525(48 \%)$ were warm or hot. Their sensitivity was $94 \%$ (257/274), specificity 67\% (544/812), positive predictive value $49 \%$ (257/525), and negative predictive value $97 \%(544 / 561)$. Two students, working independently, had remarkably similar results (sensitivities $95 \%$ and $94 \%$, positive predictive values $50 \%$ and $47 \%$ ). The table shows the data for the two groups.

\section{Comment}

This study showed that when mothers and medical students felt the children they rarely missed a child with fever, but they overestimated the number who had fever.

Because it was impractical to measure rectal temperature for cultural reasons, axillary temperature had to be used. Axillary temperature is not always accurate. One study comparing axillary and rectal temperature found means of $36.8^{\circ} \mathrm{C}$ and $37.4^{\circ} \mathrm{C}$, respectively, and a median difference of $0.5^{\circ} \mathrm{C}$ (range $-1.0^{\circ} \mathrm{C}$ to $\left.3.2^{\circ} \mathrm{C}\right)^{3}$ The difference was largest in children with high fever. The shortcomings of axillary temperature measurement might have influenced our results: positive predictive values might have been higher if rectal temperature been used.
These children felt warmer than did children in Britain, possibly because of the higher ambient temperature and the tendency to overdress. Therefore, rather than use a range derived from a different population, we calculated a normal range for the group. Defining fever as a temperature of $37.8^{\circ} \mathrm{C}$ or more was higher than the temperature used in other studies $\left(37.2^{\circ} \mathrm{C},{ }^{3} 37.4^{\circ} \mathrm{C},{ }^{4}\right.$ and $\left.37.5^{\circ} \mathrm{C}^{5}\right)$. In our study the thermometer was assiduously kept in the axilla for 3 minutes. In other studies the temperature was taken for a shorter time, which may account for the lower temperatures used.

A recent African study investigated the ability of patients (1606 men and children) or their carers to decide whether they had a fever. ${ }^{5}$ Twenty per cent had fever, but only $28 \%$ of those thought to have fever did; of those thought to have a normal temperature, $92 \%$ did.

These two studies establish that, as a screening procedure, touch will seriously overestimate the incidence of fever, but with touch, fever will rarely be missed; also, a patient who does not feel hot is very likely not to have fever. A child who feels hot needs to have a temperature taken before fever is diagnosed.

Thanks to the parents and children who took part in the study and the helpful staff of Chikankata Hospital, Zambia.

Contributors: KW and MM collected the data and were closely involved in data analysis and presentation. CM suggested the project, helped with data analysis and presentation, and is guarantor for the paper.

Funding: Financial assistance from the Commonwealth Foundation; Churchill College, Cambridge; Pembroke College, Cambridge; Medical Defence Union; Lady Valerie France; John Zeal.

Conflict of interest: None.

1 Morley CJ, Thornton AJ, Cole TJ, Hewson PH, Fowler A. Baby Check: scoring system to grade the severity of acute systemic illness in babies under 6 months old. Arch Dis Child 1991;66:100-5.

2 Clarke S. Use of thermometers in general practice. BMJ 1992;304:961-3.

3 Morley CJ, Hewson PH, Thornton AJ, Cole TJ. Axillary and recta temperature. Arch Dis Child 1992;67:122-5.

4 Shann F, MacKenzie A. Comparison of rectal, axillary and forehead temperatures. Arch Ped Adolesc Med 1996;150:74-8.

5 Einterz EM, Bates ME. Fever in Africa: do patients know when they are hot? Lancet 1997;350:781.

(Accepted 2 February 1998)

Determination of fever in children by mothers and medical students and by axillary temperature $\geqslant 37.8^{\circ} \mathrm{C}$

\begin{tabular}{lccr} 
& \multicolumn{2}{c}{ Axillary temperature } & \\
\cline { 2 - 4 } & $\geqslant \mathbf{3 7 . 8 ^ { \circ } \mathbf { C }}$ & $<\mathbf{3 7 . 8 ^ { \circ } \mathbf { C }}$ & Total \\
\hline Mothers: & 236 & 626 & 862 \\
\hline Child feels warm or hot & 221 & 353 & 574 \\
\hline Child feels normal or cold & 15 & 273 & 288 \\
\hline Students: & 274 & 812 & 1086 \\
\hline Child feels warm or hot & 257 & 268 & 525 \\
\hline Child feels normal or cold & 17 & 544 & 561 \\
\hline
\end{tabular}

\section{University of Cambridge, Department of Paediatrics, Box 226 Neonatal Intensive Care Unit, \\ Addenbrooke's \\ Hospital, Cambridge CB2 2QQ \\ Katherine \\ Whybrew, medical student \\ Matthew Murray, medical student Colin Morley, honorary consultant paediatrician \\ Correspondence to: Dr Morley morleyc@cryptic. rch.unimelb.edu.au}

BMJ 1998;317:321 